Don't Forget the Bubbles

\title{
Walking in circles: the limping child
}

Tessa Davis, ${ }^{1}$ Ben Lawton, ${ }^{2,3,4}$ Kristina Klein, ${ }^{4,5}$ Henry Goldstein ${ }^{2,3}$ and Andrew Tagg ${ }^{6}$

1. Accident and Emergency, Chelsea and Westminster Hospital, London, UK

2. Emergency Department, Lady Cilento Children's Hospital, Brisbane, Queensland, Australia

3. School of Medicine, The University of Queensland, Brisbane, Queensland, Australia

4. Emergency Department, Logan Hospital, Brisbane, Queensland, Australia

5. LifeFlight, Brisbane, Queensland, Australia

6. Emergency Department, Footscray Hospital, Melbourne, Victoria, Australia

\section{Corresponding author:}

Dr Tessa Davis, Accident and Emergency, Chelsea and Westminster Hospital, 369 Fulham Road, Chelsea, London SW10 9NH, UK. Email: tessardavis@me.com

Tessa Davis, BSc (Hons), MBChB, MA, MRCPCH, FRACP, Paediatric Emergency Trainee;

Ben Lawton, BSc (Hons), MBChB, FRACP (PEM), Paediatric Emergency Physician;

Kristina Klein, MBBS, FACEM, ???; Henry Goldstein, BPharm (Otago), MBBS (Qld),

This is the author manuscript accepted for publication and has undergone full peer review but has not been through the copyediting, typesetting, pagination and proofreading process, which may lead to differences between this version and the Version of Record. Please cite this article as doi: $10.1111 / 1742-6723.12830$

This article is protected by copyright. All rights reserved. 
Paediatric Registrar; Andrew Tagg, BSc (Hons), MBBS, MRCSEd A\&E, FACEM, Emergency Physician.

A child with a limp is a common presentation to paediatric emergency departments occurring in 1.8 per 1000 children (1). It accounts for $4 \%$ of paediatric presentations to the Paediatric Emergency Department (2). Limp, however, is merely a symptom, and not a diagnosis and is secondary to pain, weakness, or physical deformity.

There are six key diagnoses not to miss - septic arthritis, osteomyelitis, malignancy, nonaccidental injury, Perthe's disease, and a slipped upper femoral epiphysis. They all demand early intervention and treatment.

The child's age gives us a clue as to causation (see Table 1).

\begin{tabular}{|l|l|l|}
\hline Under 3s & $3-10$ years & $1-18$ years \\
\hline Fracture or soft tissue & Fracture or soft tissue & Fracture or soft tissue injury \\
injury & injury & \\
\hline Osteomyelitis or & Osteomyelitis or septic & Osteomyelitis or septic arthritis \\
\hline $\begin{array}{l}\text { Developmental } \\
\text { dysplasia of the hip }\end{array}$ & Perthritis & Perthes disease \\
\hline
\end{tabular}




\begin{tabular}{|l|l|l|}
\hline & & SUFE \\
\hline & & $\begin{array}{l}\text { Osgood-Schlatter's dsease, Sever's } \\
\text { disease, osteochondritis dissecans, } \\
\text { chondromalacia patellae }\end{array}$ \\
\hline $\begin{array}{l}\text { Also consider: malignancy, infection, metabolic, spina bifida, cerebral palsy, muscular } \\
\text { dystrophy, rheumatological condition }\end{array}$ \\
\hline
\end{tabular}

\section{The Big 6}

\section{\#1 Septic arthritis}

This is an infection of the synovium and the joint space and must be excluded if there are systemic symptoms of infection or examination shows a red, swollen, or stiff joint. The most common causative organisms vary by patient age and geography. 85\% of cases in a Sydney series were caused by staphylococcus Aureus, including one case of Methicillin Resistant Stapylococcus Aureus (MRSA). The remainder were caused by Streptococcus and Yersinia species. (3). Kingella Kingae is increasingly recognised as a cause of septic arthritis while the incidence of Haemophilus Influenzae type B related disease has decreased as immunisation against this organism has become widespread (4).

There is a risk of long term joint destruction and damage. Urgent washout and IV antibiotics are needed (5). Antibiotics should be delayed until surgery, excepting for the haemodynamically compromised child or when significant delays to surgery are unavoidable. 
The four Kocher criteria help differentiate a septic joint from transient synovitis (6): fever $>38.5^{\circ} \mathrm{C}$; non weight-bearing patient; ESR $>40 \mathrm{~mm} / \mathrm{hr}$; and a WCC $>12 \times 10^{9} / \mathrm{L}$. In Kocher's original paper three positive criteria meant there was a $93.1 \%$ chance that the patient had septic arthritis, a conclusion that has not been validated subsequently. The criteria are helpful but not as discriminatory as Kocher's original paper suggested (7).

\section{\#2 Osteomyelitis}

Osteomyelitis has similar presenting features to septic arthritis - the two diseases may occur together. Fever with decreased use of one limb is a classic combination of features. Discitis and vertebral osteomyelitis can present with subtle symptoms. Think of these when assessing a child with an abnormal gait in whom it is hard to decide which limb is being favoured or with a history of distress when the supine child's legs are lifted such as during a nappy change.

\section{\#3 Malignancy}

Symptoms such as weight loss, anorexia, night sweats or fatigue are red flags that suggest an underlying malignancy such as osteosarcoma, leukaemia or lymphoma. Examination may reveal hepatosplenomegaly, lymphadenopathy, or bruising. Back pain in a child represents a sinister presenting complaint.

\#4 Toddler's fracture 
This is an, often subtle, undisplaced tibial spiral fracture. It can be difficult to detect clinically but there may be tibial shaft tenderness most obvious with rotational force gently applied to the lower leg. It is caused by a sudden twist of the lower leg, though the history may be unclear. Spiral fractures in any child should prompt consideration of non-accidental injury. Though toddler fractures are really an exception to this rule, a full examination of the child is still appropriate to note any other injuries or bruising. These fractures should be immobilised in a long leg backslab, slightly flexed allowing the child to be buckled into a car seat, with orthopaedic follow up.

\section{\#5 Perthes Disease}

Perthes disease is idiopathic avascular necrosis of the femoral head most commonly found in boys aged between 4 and 8 years. It can present with pain in the groin or knee, or a painless limp. Hip x-rays may be normal initially. These children can have long-term problems with chronic pain and osteoarthritis.

\section{\#6 Slipped upper femoral epiphysis}

Slipped upper femoral epiphysis (SUFE) is where the proximal femoral epiphysis is displaced relative to the metaphysis. It presents as hip, thigh or knee pain (8). The classic patient is an overweight 10 to 15 year old boy. It is thought to be secondary to mechanical forces during pubertal growth, resulting in epiphyseal displacement. Examination reveals restriction of internal rotation of the hip. Treatment is surgical. SUFEs can occur bilaterally and are best diagnosed with a frog-leg lateral x-ray of both hips. 


\section{Other Diagnoses}

The most common, and benign cause of a limp is a transient synovitis. It is a diagnosis of exclusion. It is usually secondary to a viral illness and seen in children 4-8 years of age. There may be evidence of a hip effusion on ultrasound and occasionally an increase in the medial joint space on plain $\mathrm{x}$ ay of the affected hip (9). Transient synovitis should selfresolve in 3-10 days and the child will remain well looking throughout.

Non-musculosketetal causes of limp such as appendicitis, testicular torsion or atypical presentation of other abdominal pathology must be considered in the differential diagnosis.

Various types of overuse injuries such as Osgood-Schlatter's and Sever's diseases are fairly common affecting up to $50 \%$ of teenage athletes (10). Spina bifida, cerebral palsy, rickets, muscular dystrophy, juvenile idiopathic arthritis, haemarthrosis, and rheumatic fever should also be on the list of diagnoses to consider, though many of these diagnoses take time and are more likely made in the outpatient setting rather than in the Emergency Department.

\section{Examination}

With pre-school children in particular much information can be gained before laying hands on them. Watch them move around the bed or around their parent's lap, ask the parent to gently move the child's arms and legs and, if this is tolerated, take them for a walk. Blow 
some bubbles and watch how the child moves. When you do begin the physical examination, start with the non-painful limb, as this will help discriminate pain from the child just not liking you moving their legs. Just as with abdominal exams distraction is invaluable and watching the child's facial expressions will tell you much more than watching the limb you are moving. Isolate each joint in turn in moving through its range of motion and be sure to inspect the soles of the feet for splinters or other injuries. Young children will rarely walk or crawl across a room to you but if you carry them across the room and put them down they will almost always move themselves back to their caregiver. They will likely view you with suspicion after you do this though so save it until the end of the exam.

Check also for any bruising, lymphadenopathy and hepatosplenomegaly.

\section{Investigations}

Plain x-ray will exclude may of the above diagnoses including pathological fractures and those associated with non-accidental injury, which may not be indicated by the history. Full blood count (FBC), C-reactive protein (CRP), erythrocyte sedimentation rate (ESR) and a blood culture are indicated in febrile, non-weight bearing children as part of the risk stratification for septic arthritis/osteomyelitis. An FBC is prudent in children with a sub-acute or chronic limp or any systemic features suggestive of malignancy. Afebrile children with an acute history who can be persuaded to bear weight can reasonably have blood tests delayed until clearly defined follow up 24-48 hours later. This should be accompanied by safety netting advice that includes return to ED should they become febrile or systemically unwell. 
Ultrasound can identify joint effusion but as this may be present in either septic arthritis or transient synovitis this is not diagnostic. There may be acute roles for magnetic resonance imaging (MRI), or arthroscopy but their use should be discussed with the consulting orthopaedic service.

\section{Conclusion}

In the limping child we advocate a diagnostic strategy aimed at deliberately excluding the six diagnoses described above in the first instance. In a low risk child, with a normal X ray of the affected part of the limb, observation forms an important part of the diagnostic work up.

This article is protected by copyright. All rights reserved. 


\section{References}

1. Fischer S and Beattie T, The limping child: epidemiology, assessment and outcome, Journal of Bone and Joint Surgery, 1999, 81(6): 1029-1034.

2. Singer J. The cause of gait disturbance in 425 pediatric patients. Pediatric emergency care, 1985, 1(1): 7-10.

3.Goergens E, McEvoy A, Watson M, Barrett 1. Acute osteomyelitis and septic arthritis in children. Journal of Paediatrics and Child Health 2005 41(1):59-62

4.Gutierrez K. Bone and joint infections in children. Pediatric Clinics of North America 2005 $52(3): 779-794$

5. Limp: acute limp in a child, GP Update, 2015, accessed online in May 2017 at https://www.gp-update.co.uk/Latest-Updates/Acute-atraumatic-limp-in-childhood

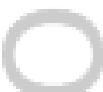

6. Kocher MS, Zurakowski D, Kasser JR. Differentiating between septic arthritis and transient synovitis of the hip in children: an evidence-based clinical prediction algorithm. Journal of Bone and Joint Surgery Am (1999) 81 (12):1662-70

This article is protected by copyright. All rights reserved. 
7. Taekema HC, Landham PR, Maconochie I. Towards evidence based medicine for paediatricians. Distinguishing between transient synovitis and septic arthritis in the limping child: how useful are clinical prediction tools? Archives of Disease in Childhood (2009) 94(2):167-168

8. Sawyers JR, Kapoor M, The limping child: a systematic approach to diagnosis, America Family Physician, 2009, 79(3): 2-15-224

9. https://radiopaedia.org/articles/transient-synovitis-of-the-hip accessed 31/5/17

10.Rejeb A, Johnson A, Vaeyens R, Horobeanu C, Farooq A, Witvrouw E. Compelling overuse injury incidence in youth multisport atheletes. European Journal of Sports Science 2017 17(4):495-502

This article is protected by copyright. All rights reserved. 


\section{University Library}

\section{- M M I E R R V A gateway to Melbourne's research publications}

Minerva Access is the Institutional Repository of The University of Melbourne

Author/s:

Davis, T;Lawton, B;Klein, K;Goldstein, H;Tagg, A

Title:

Walking in circles: The limping child

Date:

2017-08-01

Citation:

Davis, T., Lawton, B., Klein, K., Goldstein, H. \& Tagg, A. (2017). Walking in circles:

The limping child. EMERGENCY MEDICINE AUSTRALASIA, 29 (4), https:// doi.org/10.1111/1742-6723.12830.

Persistent Link:

http://hdl.handle.net/11343/293149 